\title{
Oral health researchers form Canadian network
}

$\mathrm{T}$ he newly formed National Network for Canadian Oral Health Research (NCOHR) aims to take on the next wave of challenges for oral health in Canada by connecting 10 faculties of dentistry in universities nationwide.

The network recently distributed its first round of peer-reviewed funding for research on Aboriginal oral health and chronic pain, and will be launching an online registry of experts later this month.

The network has about $\$ 800000$ to operate over the next three years, including $\$ 600000$ from the Institute of Musculoskeletal Health and Arthritis, one of the 13 branches of the Canadian Institutes of Health Research (CIHR).

"Canada is home to a number of internationally known oral health researchers. Until now, however, most have worked individually or in small groups," NCOHR founder Debora Matthews, head of periodontics at the University of Dalhousie in Halifax, Nova Scotia, writes in an email.

For example, both Robert Schroth, a professor of preventive dental science at the University of Manitoba in Winnipeg, Manitoba, and Mary McNally, an associate professor of dental clinical sciences at Dalhousie, are researching areas of Aboriginal oral health but had never met.

The network has brought them together with Aboriginal communities to strategize on what is most important for improving oral health, Schroth says. These connections are important to researching how issues differ across Canada, he adds. The team is examining areas such as child tooth decay, as well as underlying issues of transportation, access to running water and affordable food.

Oral health is directly tied to overall health, says Gilles Lavigne, a pro-

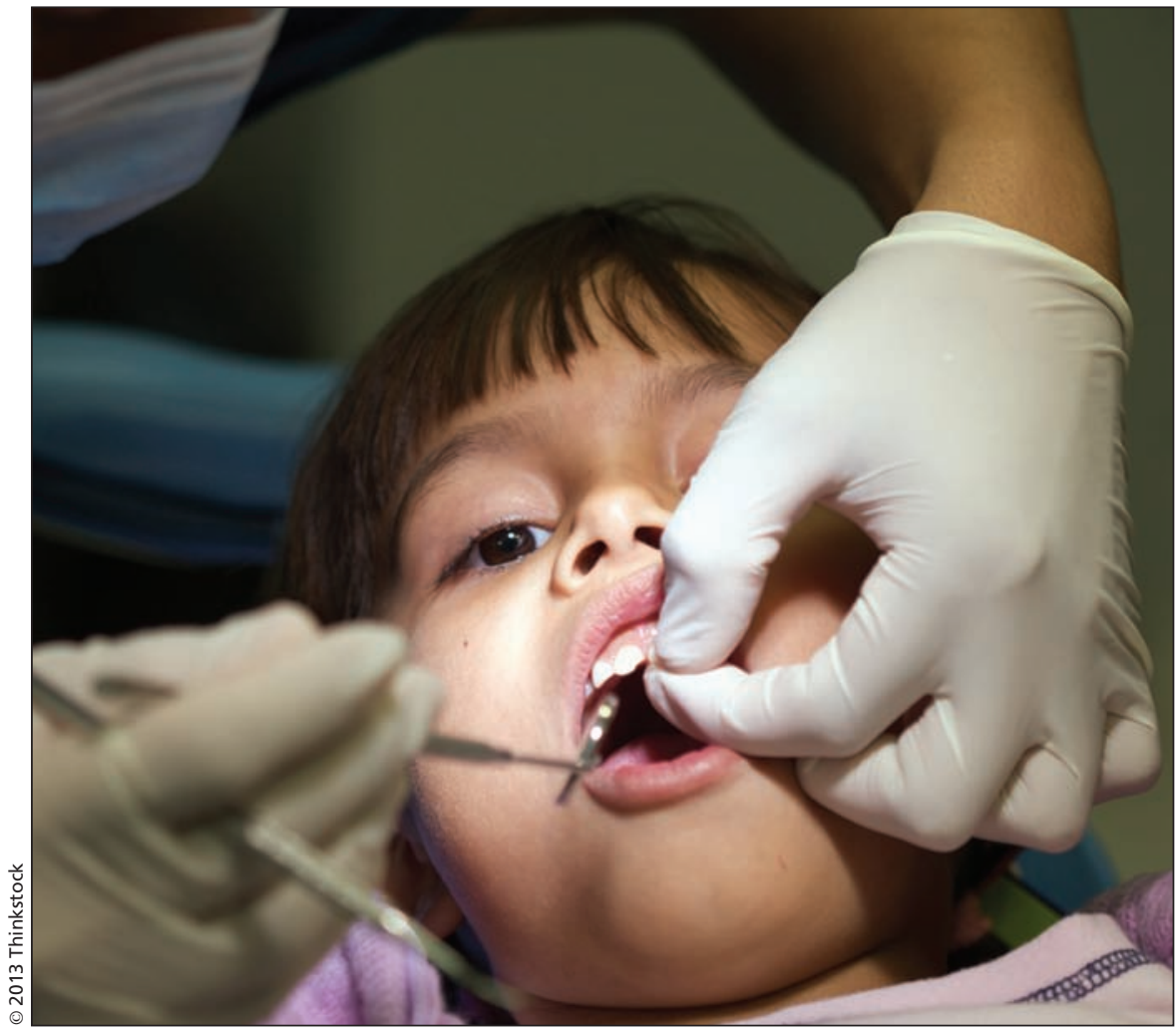

A team of researchers looking into Aboriginal oral health is examining areas such as child tooth decay.

fessor of oral health at the University of Montreal in Quebec.

For example, a reported $20 \%$ of Canadians suffer from chronic pain, including oral pain, and that number is rising as the population ages, Lavigne says. He has used his NCOHR research funds to assemble a team of experts in chronic care, patient care delivery, neurology and psychosocial aspects. They will be look at treating chronic pain with alternative medicine, how biomarkers affect the way your body recuperates from a traumatic event and how to deal with patients who are addicted to pain medication.

The new funding can only go so far, says Schroth, but it helps "so we're in a good position to submit a proposal" for other larger grants.

"Oral health research has been an under receiver of public funding," adds John O'Keefe, director of knowledge networks at the Canadian Dental Association. He says the government often treats oral health research as though it should be privately funded even though it has widespread impacts.

Lavigne says the network plays an important role for oral health research. "It's extremely difficult to find support if it isn't trendy," he says. "But sometimes our role is to figure out the upcoming problems, not just the ongoing."Juanita Bawagan, CMAJ

CMAJ 2013. DOI:10.1503/cmaj.109-4439 